\title{
Electric field effect on texture formation of mullite in spark plasma sintered $\mathrm{SiC}$ with $\mathrm{Al}_{2} \mathrm{O}_{3}-\mathrm{SiO}_{2}$ additive
}

\author{
Yutaka Shinoda $^{\mathrm{a}, *}$, Yoshikazu Suzuki ${ }^{\mathrm{b}}$ and Katsumi Yoshida ${ }^{\mathrm{c}}$ \\ a Secure Materials Center, Materials and Structures Laboratory, Tokyo Institute of \\ Technology, Yokohama, Kanagawa, 226-8503, Japan \\ ${ }^{\mathrm{b}}$ Faculty of Pure and Applied Sciences, University of Tsukuba, 1-1-1, Tennodai, Ibaraki \\ 305-8573, Japan \\ c Research Laboratory for Nuclear Reactors, Tokyo Institute of Technology, \\ 2-12-1, Ookayama, Meguro-ku, Tokyo, 152-8550, Japan
}

\begin{abstract}
Nanocrystalline SiC ceramics were sintered by spark plasma sintering, with alumina and quartz powders as additives. X-ray diffraction and transmission electron microscopy analyses revealed that mullite phase with the preferred orientation of the $c$-axis perpendicular to the compressive axis was formed in SiC ceramics sintered at 1600 and $1700{ }^{\circ} \mathrm{C}$, while mullite phase with the preferred orientation of the $c$-axis parallel to the current direction was formed in SiC ceramics sintered at 1800 and 1900 ${ }^{\circ} \mathrm{C}$.
\end{abstract}

Key words: mullite; texture; electric field; spark plasma sintering; silicon carbide

\footnotetext{
${ }^{*}$ Corresponding Author

Secure Materials Center, Materials and Structures Laboratory, Tokyo Institute of Technology, Yokohama, Kanagawa, 226-8503, Japan

Tel: +81-45-924-5335

Fax: + 81-45-924-5339

E-mail: shinoda.y.ac@m.titech.ac.jp
} 
Significant features of spark plasma sintering (SPS) are the high heating rate, the high pressure and the current effect. These features have been studied by a large number of researchers (e.g. [1]), and recently a substantial viewpoint set on SPS was published [2]. Although the role of plasma has been frequently argued, its existence has not yet been clarified. Such a fundamental investigation would help us understand the physics of the SPS process. The application of a current has an influence on mass transport. The enhancement of mass transport by the current is caused by a change in defect concentration or enhanced mobility of the defects [3]. The pressure effect on the orientation of the microstructure during SPS is well known [4]; however, the effect of the current and/or the electric field on the orientation of the microstructure has seldom been reported. Recently we found that the mullite phase in silicon carbide (SiC) ceramics sintered by SPS had a texture in which the c-axis was oriented parallel to the SPS current direction [5]. In this paper, the effect of the electric field on the mullite texture is clarified in detail.

The starting powder was ultrafine $\beta$-SiC, with a mean particle size of $<50 \mathrm{~nm}$ (MTI Co., Richmond, CA). The SiC powder was mixed with $\alpha-\mathrm{Al}_{2} \mathrm{O}_{3}$ powder with a mean particle size of $0.2 \mu \mathrm{m}$ (AKP-50, Sumitomo Chemical Co., Ltd, Tokyo, Japan) and $\mathrm{SiO}_{2}$ (quartz) powder with a mean particle size of $0.8 \mu \mathrm{m}$ (Kojundo Chemical Co., Ltd, Saitama, Japan) as sintering additives. The composition was designed such that 20 vol.\% 3/2 mullite (i.e. $\mathrm{Al}_{6} \mathrm{Si}_{2} \mathrm{O}_{13}$ ) phase was formed in 80 vol.\% $\mathrm{SiC}$ ceramic. The $\mathrm{SiC}$ and additive powders were mixed by planetary ball milling. The mixed powder was sintered via SPS at $1600-1900{ }^{\circ} \mathrm{C}$ and at a pressure of $25-100 \mathrm{MPa}$, with a heating rate of $50{ }^{\circ} \mathrm{C} \mathrm{min}{ }^{-1}$, followed by soaking for $0-10$ min under a nitrogen atmosphere. In this paper, the $\mathrm{SiC}$ with added $\mathrm{Al}_{2} \mathrm{O}_{3}$ and $\mathrm{SiO}_{2}$ is denoted as $\mathrm{AS}-\mathrm{SiC}$.

Crystalline phase identification of the samples was conducted by using X-ray diffraction (XRD) with a copper target (Rint 2500, Rigaku, Tokyo, Japan). Transmission electron microscopy (TEM) observation of the microstructure was performed with a field emission transmission electron microscope (JEM2100F, JEOL Ltd., Tokyo, Japan) at $200 \mathrm{kV}$. The analytical work was performed by energy-dispersive X-ray spectroscopy (EDS; JET2300T, JEOL Ltd., Tokyo, Japan) with the scanning transmission electron microscopy (STEM) mode using a probe size of $1 \mathrm{~nm}$. The composition of mullite phase was assessed using k-factors which were calibrated by the standard 3/2 mullite powder.

AS-SiC sintered by SPS at $>1700{ }^{\circ} \mathrm{C}$ was almost fully densified. However, the relative density of the sample sintered at $1600{ }^{\circ} \mathrm{C}$ was $\sim 86 \%$.

XRD measurements were conducted on the compressive planes of the sintered samples. The results revealed that mullite phase was formed in the sintered AS-SiC as follows:

$(2+x) \mathrm{Al}_{2} \mathrm{O}_{3}+2(1-\mathrm{x}) \mathrm{SiO}_{2}=>\mathrm{Al}_{4+2 x} \mathrm{Si}_{2-2 \mathrm{x}} \mathrm{O}_{10-\mathrm{x}}$

with $x$ ranging between about 0.2 and $0.9\left(\sim 55-90\right.$ mol.\% $\left.\mathrm{Al}_{2} \mathrm{O}_{3}\right)$ [6]. 
The orientation of the mullite in AS-SiC sintered by SPS was clearly different at the different sintering temperatures. Figure 1 shows typical XRD patterns of AS-SiC sintered at 1700 and $1800{ }^{\circ} \mathrm{C}$. The peaks from the mullite (001) and (002) planes, i.e. the $c$-axis planes, are observed at $2 \theta$ of $\sim 31.0$ and $\sim 64.6^{\circ}$, respectively. Inherently, the relative intensity of the peak from the (001) and (002) planes are 20 and 18\%, respectively, of the intensity of the strongest peak from the (210) plane, which is perpendicular to the $c$-axis planes at $2 \theta$ of $\sim 26.3^{\circ}$ (JCPDS 15-0776). In AS-SiC sintered at $1800{ }^{\circ} \mathrm{C}$, however, the peak intensities from the $c$-axis planes of mullite were stronger than that from the (210) plane. This means that the $c$-axis planes of mullite are orientated parallel to the SPS compressive plane. The AS-SiC sintered at $1900{ }^{\circ} \mathrm{C}$ showed a similar feature. These results were similar to those in our previous report on the mullite texture in AT-SiC ceramics SPS sintered at $1800^{\circ} \mathrm{C}$ [5]. On the other hand, the peaks from $c$-axis planes of mullite were hardly observed in AS-SiC sintered at 1600 and $1700{ }^{\circ} \mathrm{C}$. This means the $c$-axis plane of mullite was oriented perpendicular to the compressive plane during sintering at lower temperatures. The insets in the Figure 1 display the peaks from the (120), (210) and (001) planes of mullite. The peaks from the (120) and (210) planes of mullite in AS-SiC sintered at $1700{ }^{\circ} \mathrm{C}$ are clearly distinguished; however, those from the mullite in AS-SiC sintered at $1800{ }^{\circ} \mathrm{C}$ overlap. As shown in the above chemical equation, mullite crystals can possess variable aluminum to silicon ratios. The equilibrium crystal structure of mullite with a composition of $3 \mathrm{Al}_{2} \mathrm{O}_{3} \cdot 2 \mathrm{SiO}_{2}$ (3/2 mullite) is orthorhombic, with lattice parameters of $a$ $<b$. Then the peaks from the (120) and (210) planes at the $2 \theta$ of approximately $26^{\circ}$ are clearly distinguishable [7]. The $a$ lattice constant increases linearly and the $b$ lattice constant decreases slightly as the $\mathrm{Al}_{2} \mathrm{O}_{3}$ content increases [6]. As a result, the $\mathrm{Al}_{2} \mathrm{O}_{3}$-rich mullite has the crystal structure with $a \approx b$, a so-called pseudotetragonal structure [7], and the two peaks from the (120) and (210) planes overlap. Because of this, the $\mathrm{Al}_{2} \mathrm{O}_{3}$ contents in AS-SiC sintered at a temperature above $1800^{\circ} \mathrm{C}$ were suggested to be higher than those sintered at a temperature below $1800^{\circ} \mathrm{C}$. In this way, AS-SiC sintered by SPS showed contrasting texture and crystal structure in mullite phase according to the sintering temperatures.

In order to ascertain the effect of the electric field on the texture formation, the SPS was performed by using pure hafnia $\left(\mathrm{HfO}_{2}\right)$ plates with a thickness of $1.5 \mathrm{~mm}$ as insulators. The AS-SiC powder compacts were set between $\mathrm{HfO}_{2}$ insulation plates and sintered under the same conditions as without insulators. Here, AS-SiC sintered by SPS with and without $\mathrm{HfO}_{2}$ insulators are denoted as standard $\mathrm{AS}-\mathrm{SiC}$ and insulated AS-SiC, respectively.

Figure 2 shows the ratio of the integrated intensity from the (001) plane, $I(001)$, to the sum of the integrated intensities from the (210) and (120) planes, $\left\{I_{(210)}+I_{(120)}\right\}$, of mullite crystal in AS-SiC sintered by SPS at various sintering temperatures. The data of commercial mullite powder (Grade: KM102, KCM Corporation Co., Ltd.) is also 
presented. The dashed line shows the ratio of the peak intensity from the (001) plane to the sum of the peak intensities from the (210) and (120) planes, from the data of JCPDS 15-0776. The sample surface was X-ray irradiated parallel to the compressive plane. The ratio of the integrated intensities for the commercial mullite powder was $\sim 0.11$. This value agreed with the ratio of peak intensities from the JCPDS 15-0776 data.

The ratios of integrated intensities for the standard AS-SiC sintered at 1800 and $1900{ }^{\circ} \mathrm{C}$, were much higher than that for the commercial mullite powder consisting of particles with an almost random orientation, whereas the ratios of integrated intensities for the standard AS-SiC sintered at 1600 and $1700{ }^{\circ} \mathrm{C}$ were much lower than that for the commercial mullite powder. These results clearly show the temperature dependence of the mullite texture; that is to say, the $c$-axis of mullite is preferentially oriented parallel and perpendicular to the compressive axis at higher and lower temperatures, respectively. On the other hand, the ratios of the integrated intensities for the insulated AS-SiC were at the same level as the standard AS-SiC at 1600 and $1700{ }^{\circ} \mathrm{C}$. At 1800 and $1900{ }^{\circ} \mathrm{C}$, however, the ratios of the integrated intensities of the insulated AS-SiC were still at a low level and lower than that for the commercial mullite powder. This suggests that the mullite texture was affected by the electric field during SPS at higher temperatures, while the electric field has no influence on the texture formation at lower temperatures.

To confirm the effect of the electric field and also examine the effect of applied pressure during sintering on the mullite texture, AS-SiC was sintered by hot pressing in the temperature range of $1700-1950^{\circ} \mathrm{C}$ in a nitrogen atmosphere under the same pressure conditions with SPS. The trend of the texture formation did not agree with that of the standard AS-SiC but did agree with the insulated AS-SiC sintered by SPS, as shown in Figure 2. Thus, the mullite texture in the standard AS-SiC sintered at 1800 and $1900{ }^{\circ} \mathrm{C}$ has a unique microstructure - and this texture was caused by the effect of the electric field during SPS. The AS-SiC sintered without pressure in the furnace under a nitrogen atmosphere at 1600 and $1700{ }^{\circ} \mathrm{C}$ had no mullite texture and the ratios of integrated intensities for those samples were almost at same level as that of the commercial mullite powder. Therefore, the formation of the mullite texture at lower temperatures can be attribute to the applied pressure during sintering.

Figure 3(a) and (b) present TEM images of the typical microstructures, with fine grain sizes of $\sim 100 \mathrm{~nm}$, of the standard AS-SiC sintered by SPS at 1700 and $1800{ }^{\circ} \mathrm{C}$, respectively. The incident direction of the electron beam was nearly parallel to the SPS current direction. There were no distinct differences in the morphology of the SiC grains or the other phases between the both samples. The aluminosilicate glass existed at the multiple grain junctions. The crystallized mullite phase also surrounded the $\mathrm{SiC}$ grains like a glassy phase, as shown in STEM images (Fig. 3(c) and (d)). STEM/EDS analysis revealed that the mullite phase in the standard AS-SiC sintered at $1800{ }^{\circ} \mathrm{C}$ tended to show a higher $\mathrm{Al} / \mathrm{Si}$ ratio than that sintered at $1700{ }^{\circ} \mathrm{C}$ (Fig. 4), which suggests that the 
composition of the mullite phase in the AS-SiC sintered at $1800{ }^{\circ} \mathrm{C}$ was $\mathrm{Al}_{2} \mathrm{O}_{3}$ rich.

Mullite crystal growth usually shows acicular morphology, with the needle axis parallel to the $c$-axis [8]. This can be explained by the periodic bond chain model of Hartman and Perdok [9], in which the surface energy in the (001) plane is higher than those in the $\{h k 0\}$ planes. Therefore, the crystal growth is enhanced parallel to the $c$-axis. The mullite crystal begins to be formed by the reaction between $\mathrm{SiO}_{2}$ and $\mathrm{Al}_{2} \mathrm{O}_{3}$ in aluminosilicate melt at approximately $1500{ }^{\circ} \mathrm{C}$. The needle-like crystals formed during sintering aligned parallel to the compressive plane with densification. Finally, most of these grains grow in the aluminosilicate melt, keeping their crystallographic orientation and surrounding the $\mathrm{SiC}$ grains. Consequently, the $c$-axis of the mullite phase in the AS-SiC sintered at lower temperatures was oriented parallel to the compressive plane in both cases of SPS and hot pressing. This type of mullite crystal, which was formed by solid-state reaction, i.e. sintered mullite, consists of 3/2 mullite (i.e. $\mathrm{Al}_{6} \mathrm{Si}_{2} \mathrm{O}_{13}$ ) [10].

The mullite crystal formed by crystallizing of aluminosilicate melt, i.e. fused mullite, consists of mullite containing a larger amount of $\mathrm{Al}_{2} \mathrm{O}_{3}$ (as 2/1 mullite, i.e. $\left.\mathrm{Al}_{4} \mathrm{SiO}_{8}\right)$ ) [11,12]. The XRD results suggested the AS-SiC sintered by SPS at $1800{ }^{\circ} \mathrm{C}$ was alumina-rich mullite. The sintering temperature is lower than the melting temperature of mullite $\left(\sim 1830{ }^{\circ} \mathrm{C}\right)$; however, the real temperature of a sample during sintering by SPS has been reported to be higher than that measured on the surface of a graphite mold by a pyrometer [13]. It is thus possible that the mullite phase melted during SPS even at $1800{ }^{\circ} \mathrm{C}$. We can therefore concluded that the mullite phase in AS-SiC sintered by SPS at $>1800{ }^{\circ} \mathrm{C}$ dissolved into aluminosilicate melt and precipitated as the alumina-rich mullite phase, thus forming the texture during sintering.

The alignment of carbon nanotubes (CNTs) in polymers and other viscous media under electric fields has been studied by many researchers [14,15]. In this case, the CNTs rotate in parallel to the direction of the electric field due to the electrostatic polarization along the tube axis direction. This orientation controlling by the electric field is also applicable for the insulating materials. Liu et al. [16] reported that a completely (001)-oriented ferroelectric $\mathrm{LiNbO}_{3}$ film grew on silicon wafer by applying an electric field using a pulsed laser deposition technique. The orientation of the deposited films was determined at a very early nucleation stage. The authors analyzed the change of the total free energy $\Delta G$ during the formation of a nucleus according to the Volmer-Weber theory on nucleation [17], considering the contribution of electrostatic energy resulting from the spontaneous polarization of $\mathrm{LiNbO}_{3}$. In case of the mullite nucleus in AS-SiC, the origin of the electrostatic energy is dielectric polarization of mullite. $\Delta G$ is then described as follows:

$\Delta G=-V\left(\Delta \mu+P_{d} E_{f} \cos \theta\right)+S \gamma$

where $\Delta \mu$ is the chemical potential of grains per unit volume, $V$ is the volume of a nucleus, $S$ is the surface area, $\gamma$ is the interfacial energy per unit area, $P_{d}$ is the dielectric 
polarization of mullite, $E_{f}$ is the electric field and $\theta$ is the angle between the electric field and the polarization direction. The orientation of the mullite nuclei is decided by the interaction between the polarization in the mullite nucleus and the electric field; therefore it is influenced by the anisotropy of the dielectric polarization in the mullite. The electrical conductivity $(\sigma)$ in mullite has anisotropy characterized by $\sigma_{[001]}>\sigma_{[100]}$ $\approx \sigma_{[010]}$ above $800^{\circ} \mathrm{C}$ and it increases with temperature, thus increasing the contribution of the ionic conductivity [18]. From this, the dielectric polarization is assumed to be formed preferentially in the mullite nucleus along the $c$-axis direction upon application of an electric field. The mullite nuclei are thought to grow, making the polarization direction coincide with the direction of the electric field during cooling. Consequently, the $c$-axis of mullite is oriented parallel to the direction of the electric field.

The mullite texture in $\mathrm{SiC}$ ceramics sintered by SPS with $\mathrm{Al}_{2} \mathrm{O}_{3}$ and $\mathrm{SiO}_{2}$ powder as additives was classified according to the sintering temperature. At a temperature below $1800{ }^{\circ} \mathrm{C}$, the $c$-axis of the mullite was perpendicular to the compressive axis because the needle-like mullite nuclei along the $c$-axis were formed by the solid-state reacting between silica and alumina during sintering. At a temperature above $1800{ }^{\circ} \mathrm{C}$, the $c$-axis was parallel to the electric field direction because the preferred polarization along the $c$-axis was formed during the mullite nucleation from the aluminosilicate melt.

\section{Acknowledgment}

This work was supported by Collaborative Research Project of the Materials and Structures Laboratory, Tokyo Institute of Technology. 


\section{References}

[1] Z. A. Munir, U. Anselmi-Tamburini, M. Ohyanagi, J. Mater. Sci. 41 (2006) 763.

[2] S.H. Risbud, Y.-H. Han, Scr. Mater. 69 (2013) 105-174.

[3] U. Anselmi-Tamburini, J. E. Garay, Z. A. Munir, Mater. Sci. Eng, A 407 (2005) 24.

[4] J. Liu, Z. Shen, M. Nygren, Y. Kan, P. Wang, J. Eur. Ceram. Soc. 26 (2006) 3233.

[5] Y. Shinoda, Y. Suzuki, K. Yoshida, J. Asian Ceram. Soc. 1 (2013) 267.

[6] R.X. Fischer, H. Schneider, D. Voll, J. Eur. Ceram. Soc. 16 (1996) 109.

[7] D. X. Li., W.J. Thomson, J. Mater. Res. 6 (1991) 819.

[8] M. A. Sainz, F.J. Serrano, J. Bastida, A. Caballero, J. Eur. Ceram. Soc. 17 (1997) 1277.

[9] P. Hartman, W.G. Perdok, Acta Crystallogr. 8 (1955) 49.

[10] I.A. Aksay, J.A. Pask, J. Am. Ceram. Soc. 58 (1975) 507.

[11] S.H. Risbud, J.A. Pask, J. Am. Ceram. Soc. 60 (1977) 418.

[12] S.H. Risbud, J.A. Pask, J. Am. Ceram. Soc. 61 (1978) 63.

[13] J. Langer, D.V. Quach, J.R. Groza, O. Guillon, Int. J. Appl. Ceram. Tec. 8 (2011) 1459.

[14] A.I. Oliva-Aviles, F. Aviles, V. Sosa, A.I. Oliva, F. Gamboa, Nanotechnology 23 (2012) 465710.

[15] M. Monti, M. Natali, L. Torre, J. M. Kenny, Carbon 50 (2012) 2453.

[16] Z. G. Liu, W.S. Hu, X.L. Guo, J.M. Liu, D. Feng, Appl. Surf. Sci. 109(110) (1997) 520.

[17] M. Volmer, A. Weber, Z. Phys. Chem. 119 (1926) 227.

[18] M. Malki, J. Schreuer, H. Schneider, Am. Mine. 99 (2014) 1104. 

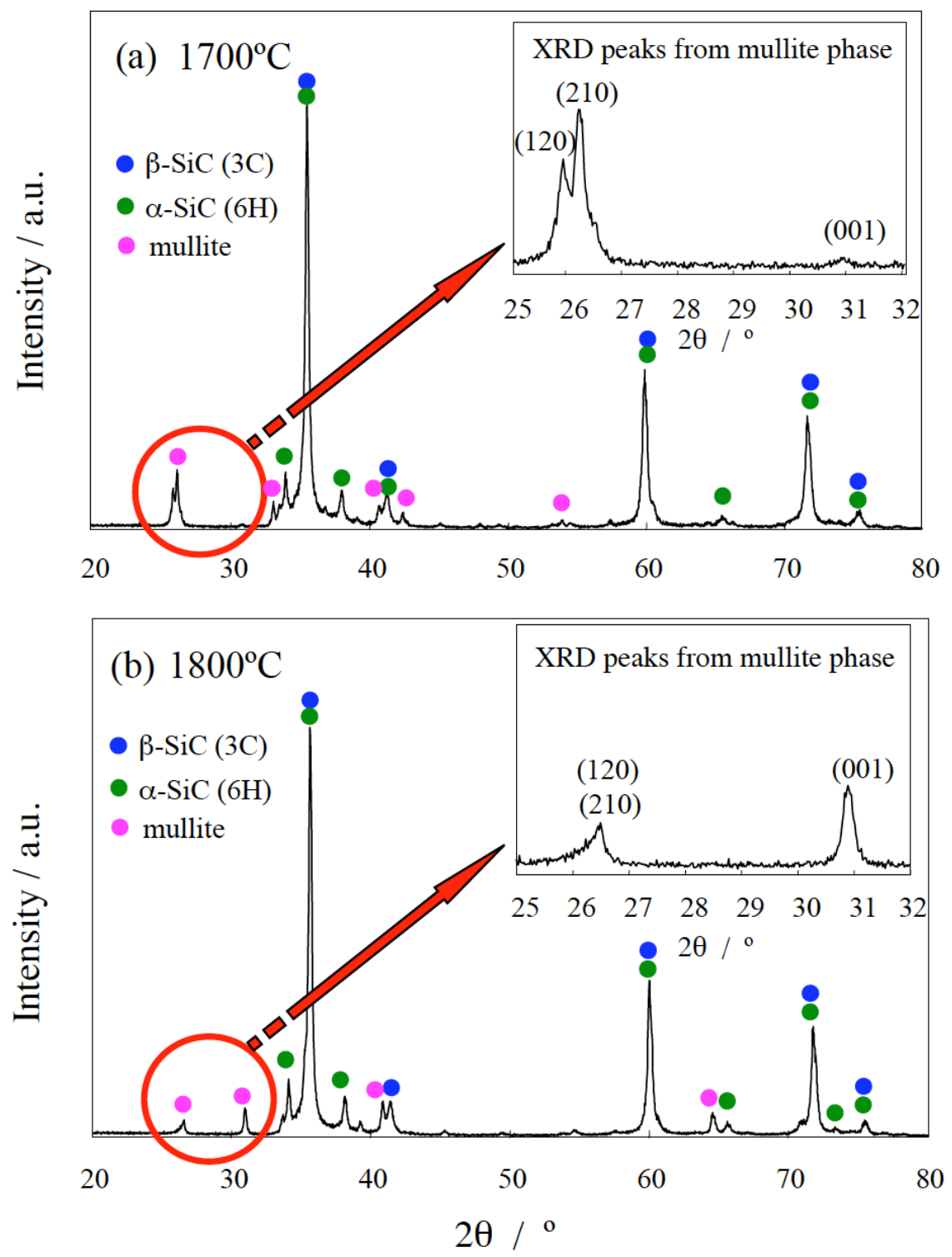

Figure 1. XRD patterns of AS-SiC sintered by SPS at (a) $1700{ }^{\circ} \mathrm{C}$ and (b) $1800{ }^{\circ} \mathrm{C}$. The sample surface was X-irradiated parallel to the compressive plane. 


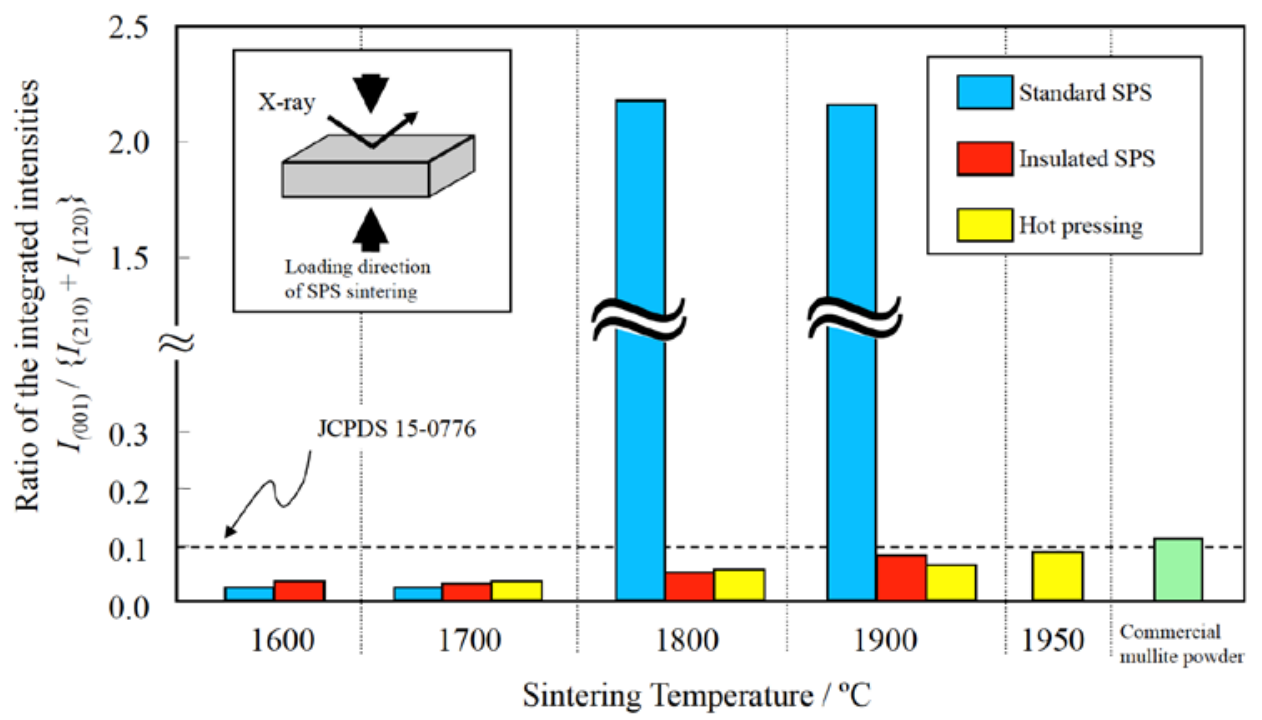

Figure 2. Ratio of the integrated intensity from the (001) plane, $I_{(001)}$, to the sum of the integrated intensities from the (210) and (120) planes, $\left\{I_{(210)}+I\right.$ ${ }_{(120)}$, of mullite in AS-SiC sintered by SPS at various temperatures. The AS-SiC was sintered with (insulated AS-SiC) and without (standard AS-SiC) hafnia insulators. Data for the commercial mullite powder and the hot pressed AS-SiC are also presented. 


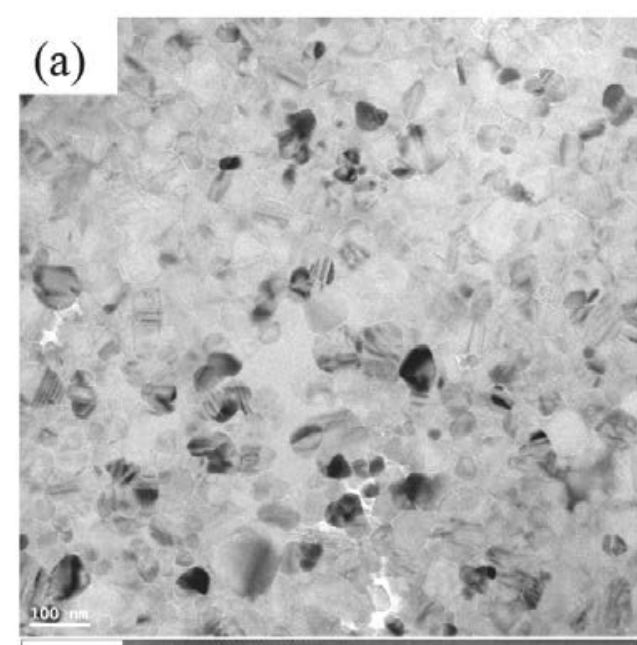

(b)

(c)
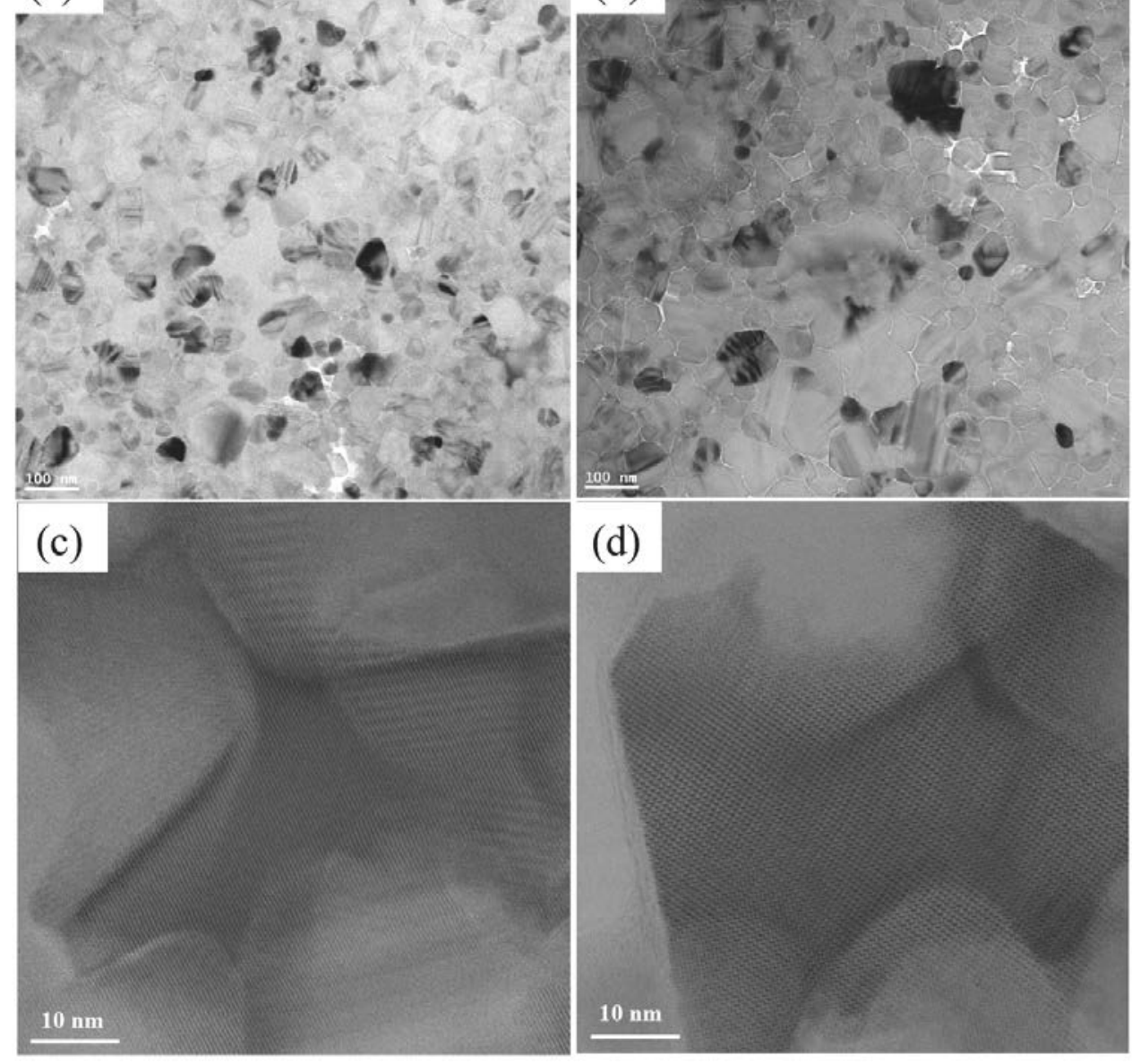

(d)

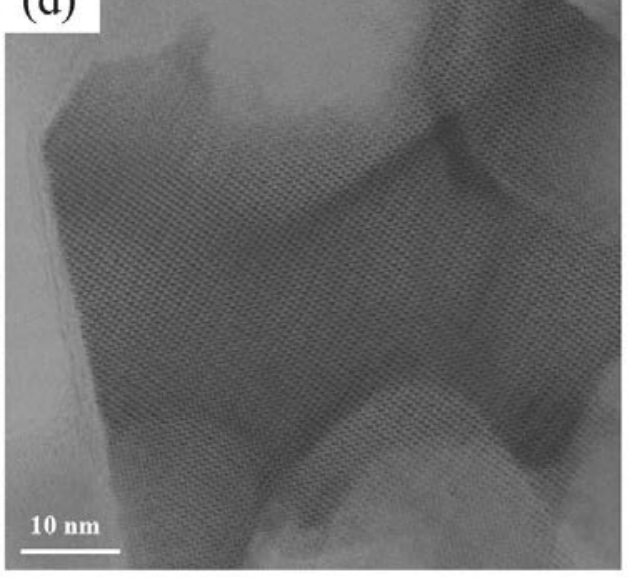

Figure 3. TEM images of the standard AS-SiC sintered at (a) $1700{ }^{\circ} \mathrm{C}$ and (b) $1800{ }^{\circ} \mathrm{C}$, and STEM images of the mullite phase in the standard AS-SiC sintered by SPS at (c) $1700{ }^{\circ} \mathrm{C}$ and (d) $1800{ }^{\circ} \mathrm{C}$. The incident direction of the electron beam was nearly parallel to the SPS current direction. 


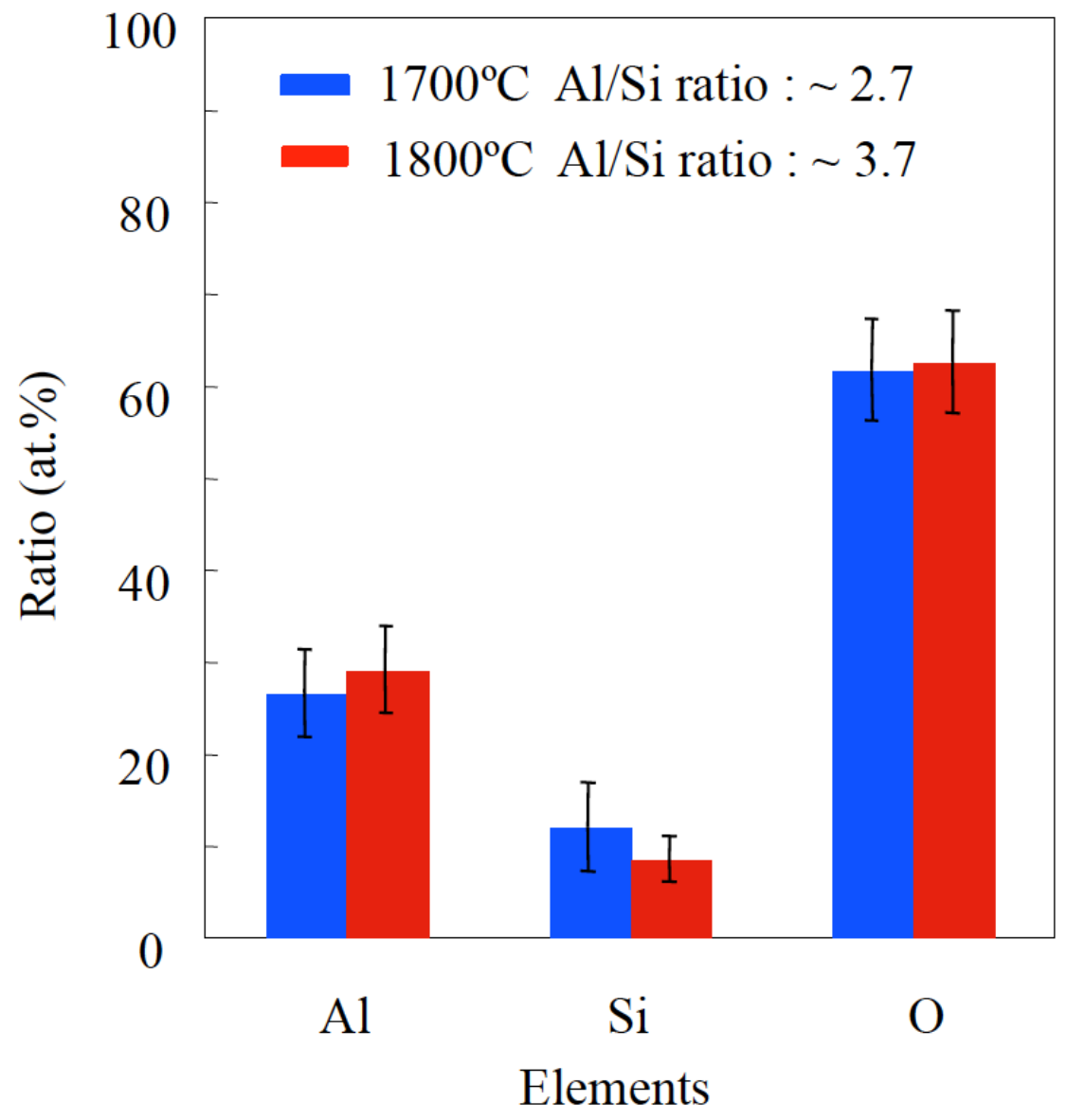

Figure 4. Atomic ratios of $\mathrm{Al}, \mathrm{Si}$ and $\mathrm{O}$ elements in the mullite phase analyzed by STEM/EDS in the standard AS-SiC sintered by SPS. 